\title{
Hubungan Lama Menderita dan Indeks Massa Tubuh terhadap Gejala Neuropati pada Penderita Diabetes Melitus di Wilayah Kerja Puskesmas Kenali Besar
}

\author{
Hasyim Kadri ${ }^{1}$, Nurfitriani ${ }^{2}$ \\ ${ }^{1}$ Program Studi S1 Keperawatan, Sekolah Tinggi Ilmu Kesehatan Baiturrahim \\ ${ }^{2}$ Program Studi DIII Keperawatan, Sekolah Tinggi Ilmu Kesehatan Baiturrahim \\ Email :h451mkadri87@gmail.com
}

Submitted : 20/08/2021

Accepted: 10-09-2021

Published: 15 /09/2021

\begin{abstract}
Advances in technology have led to changes in lifestyle, such as the availability of various technological products that make it easier for human activities to become less mobile. Changes in behavior and eating patterns that lead to fast food with high energy, fat and low fiber content contribute greatly to the increase in the prevalence of diabetes mellitus. The purpose of this study was to determine the relationship between length of stay and body mass index on symptoms of neuropathy in patients with diabetes mellitus in the Working Area of the Kenali Besar Public Health Center, Jambi City. This research is a quantitative research with a cross sectional design. The population in this study were all people with diabetes mellitus in the Working Area of the Kenali Besar Health Center totaling 200 people, with a total sampling technique with a sample of 178 people. Data were obtained using a questionnaire. Statistical test using Chi-square test. The results showed that most of the respondents suffered from diabetes mellitus $>5$ years $(83.7 \%)$, overweight (69.1\%) and had symptoms of severe neuropathy (57.3\%). There is a significant relationship between the duration of suffering from diabetes mellitus with symptoms of neuropathy with $p$-value $=0.012$. There is a significant relationship between body mass index and symptoms of neuropathy in patients with diabetes mellitus with $p$-value $=0.022$.
\end{abstract}

Keywords: body mass index, diabetes mellitus, length of suffering, symptoms of neuropathy

\begin{abstract}
Abstrak
Kemajuan di bidang teknologi menyebabkan perubahan pada gaya hidup seperti tersedianya berbagai produk teknologi yang memberikan kemudahan aktivitas manusia menjadi kurang bergerak. Perubahan perilaku dan pola makan yang mengarah pada makanan siap saji dengan kandungan tinggi energi, lemak dan rendah serat berkontribusi besar pada peningkatan prevalensi diabetes mellitus. Tujuan penelitian ini untuk mengetahui hubungan lama menderita dan indeks masa tubuh terhadap gejala neuropati pada penderita diabetes mellitus di Wilayah Kerja Puskesmas Kenali Besar Kota Jambi. Penelitian ini merupakan penelitian kuantitatif dengan desain cross sectional. Populasi pada penelitian ini adalah seluruh penderita diabetes mellitus di Wilayah Kerja Puskesmas Kenali Besar berjumlah 178 orang, dengan teknik Total sampling dengan sampel sebesar 178 orang. Data diperoleh menggunakan kuesioner. Uji statistik menggunakan uji Chisquare. Hasil penelitian diperoleh sebagaian besar responden menderita diabetes mellitus $>5$ tahun $(83,7 \%)$, berat badan lebih $(69,1 \%)$ dan mempunyai gejala neuropati Berat $(57,3 \%)$. Ada hubungan yang bermakna antara lama menderita diabetes mellitus dengan gejala neuropati dengan $p$ value $=0,012$. Ada hubungan yang bermakna antara indeks masa tubuh dengan gejala neuropati pada penderita diabetes mellitus dengan $p$-value $=0,022$.
\end{abstract}

Kata Kunci : diabetes mellitus, gejala neuropati, lama menderita, indexs masa tubuh 


\section{PENDAHULUAN}

Diabetes melitus (DM) merupakan salah satu penyakit yang prevalensinya terus mengalami peningkatan di dunia, baik pada negara maju ataupun negara berkembang, sehingga dikatakan bahwa diabetes melitus sudah menjadi masalah kesehatan penyakit global pada masyarakat. WHO memperkirakan bahwa lebih dari 346 juta orang di seluruh dunia mengidap diabetes. Jumlah ini kemungkinan akan lebih dari dua kali lipat pada tahun 2030 tanpa intervensi. Hampir $80 \%$ kematian diabetes terjadi di negara berpenghasilan rendah dan menengah (Suiraoka, 2012).

Penderita DM di Indonesia diprediksi akan mengalami peningkatan yang cukup besar pada tahun-tahun mendatang. World Health Organization (WHO) memprediksi Indonesia akan mengalami kenaikan jumlah penyandang DM dari 8,4 juta pada tahun 2000 menjadi sekitar 21,3 juta pada tahun 2030. Berdasarkan data diatas maka dapat disimpulkan adanya peningkatan jumlah penyandang DM sebanyak 2-3 kali lipat pada tahun 2030 (Ernawati, 2013).

Diabetes melitus adalah keadaan hiperglikemia kronik yang disertai berbagai kelainan metabolik akibat gangguan hormonal yang menimbulkan berbagai komplikasi kronik pada mata, ginjal, saraf dan pembuluh darah. Diabetes melitus klinis adalah suatu sindroma gangguan metabolisme dengan hiperglikemia yang tidak semestinya sebagai akibat defisiensi sekresi insulin atau berkurangnya efektifitas biologis dari insulin atau keduanya (Rendy, 2012).

Menurut Soegondo dan Subekti 2009 dalam Damayanti (2015) DM terjadi jika insulin yang dihasikan tidak cukup untuk mempertahankan gula darah dalam batas normal atau jika sel tubuh tidak mampu berespon dengan tepat sehingga akan muncul keluhan khas DM berupa poliuria, polidipsi, polifagia, penurunan berat badan, kelemahan, kesemutan, pandangan kabur dan disfungsi ereksi pada laki-laki dan pruritus vulvae pada wanita.

Kemajuan di bidang teknologi menyebabkan perubahan pada gaya hidup seperti tersedianya berbagai produk teknologi yang memberikan kemudahan aktivitas manusia menjadi kurang bergerak. Perubahan perilaku dan pola makan yang mengarah pada makanan siap saji dengan kandungan tinggi energi, lemak dan rendah serat berkontribusi besar pada peningkatan prevalensi DM (Suiraoka, 2012).

Pertambahan jumlah pasien DM dan komplikasinya disebabkan oleh perubahan pola hidup masyarakat yang semakin tidak sehat. DM berhubungan dengan obesitas yang dipengaruhi oleh diet yang tidak sehat dan kurangnya aktivitas. Berdasarkan pola konsumsi makanan berisiko rata-rata penduduk Indonesia yang berumur $>10$ tahun, salah satunya adalah mengkonsumsi makanan manis yaitu sebesar $68,1 \%$ (Damayanti, 2015).

Neuropati sensorik adalah jenis neuropati perifer yang terjadi ketika terjadi gangguan pada saraf yang mengirim sinyal sensasi, seperti sensasi sentuhan, suhu, atau nyeri. Gejala umum yang mungkin timbul ketika mengalami neuropati perifer. Neuropati Otonom ini terjadi ketika ada cedera pada saraf otonom, yaitu saraf yang mengontrol proses tubuh yang bekerja secara otomatis (tanpa perintah), seperti saluran pencernaan, kandung kemih, atau tekanan darah. Neoropati motorik terjadi ketika terdapat gangguan pada saraf yang mengontrol gerakan tubuh. (Galvani 2020)

Pasien DM yang mengalami hiperglikemia dalam waktu yang lama akan mengakibatkan aktivitas jalur poliyol meningkat dimana glukosa akan di ubah menjadi sorbitol dengan bantuan enzim aldose-reduktase. Neuropati dapat diturunkan kejadiannya dengan mencegah kerusakan vascular melalui modifikasi faktor resiko kardiovaskuler seperti trigleserida yang tinggi, indeks masa tubuh, (Ernawati, 2013). 
Komplikasi neuropati menimbulkan permasalahan di kaki, yaitu berupa ulkus kaki diabetik, DM yang dialami pasien tidak terdiagnosis selama beberapa tahun. Masalah kaki juga merupakan masalah yang umum pada pasien dengan diabetes dan hal ini menjadi cukup berat akibat adanya ulkus serta infeksi, bahkan akhirnya dapat menyebabkan amputasi (Damayanti, 2015).

Hasil penelitian yang dilakukan Anggun (2020), tentang faktor-faktor yang mempengaruhi derajat keparahan neuropati pada pasien diabetes melitus. Adalah usia, lama menderita diabetes, HbA1c, defisiensi vitamin $\mathrm{D}$, body mass index, kadar lipid, dan adanya plak pada arteri karotis. Usia merupakan faktor yang paling banyak ditemukan pada artikel penelitian. Faktor yang dapat dimodifikasi dalam pengelolaan neuropati adalah kontrol glikemik, defisiensi vitamin $\mathrm{D}$, body mass index, dislipidemia dan penanganan aterosklerosis.

Hasil penelitian yang dilakukan Rima (2020), tentang faktor resiko neuropati pada pasien diabetes melitus. Hasilnya didapatkan 16 artikel yang sesuai dengan topik dan melalui peninjauan diketahui faktor resiko neuropati pada pasien diabetes mellitus adalah usia tua, jenis kelamin laki-laki, lamanya menderita diabetes melitus, kontrol glikemik buruk, retinopati, nefropati, dan faktor resiko penyakit kardiovaskular sepert: obesitas, overweight, hipertensi, dan dislipidemia.

Penelitisn Regina (2018) hubungan antara IMT dengan Neuropati Diabetika pada pasien DM Tipe 2 di rumah sakit Dr. Muhammad Hoesin Palembang tahun 2018. : Hasil dari 28 pasien, didapatkan pasien yang menderita DM tipe 2 yang paling banyak diderita oleh laki-laki sebanyak 18 orang $(64.3 \%)$, terdapat 15 orang $(53.6 \%)$ golongan usia 45-55 tahun, 17 orang $(60.7 \%)$ golongan IMT Normal, yang menderita komplikasi Neuropati Diabetika sebanyak 7 orang (25\%), ada hubungan antara IMT dengan neuropati diabetika pada pasien DM.

Berdasarkan data Dinas Kesehatan Kota Jambi mencatat jumlah penderita diabetes mellitus dari 20 Puskesmas di Kota Jambi. Jumlah penderita diabetes melitus tahun 2019 meningkat sebesar 55,02\% dari tahun 2018, tahun 2020 meningkat kembali sebesar 2,86\% dari tahun 2019. Jumlah penderita diabetes melitus di Puskesmas Kenali Besar tahun 2020 ada 200 orang

Berdasarkan uraian latar belakang diatas, maka peneliti melakukan penelitian terhadap hubungan lama menderita dan indeks masa tubuh dengan gejala neuropati pada penderita diabetes mellitus di Wilayah Kerja Puskesmas Kenali Besar Kota Jambi.

\section{METODE PENELITIAN}

Penelitian ini penelitian kuantitatif dengan desain cross sectional. Penelitian ini dilakukan diwilayah kerja Puskesmas Kenali Besar pada bulan Mei-Juni 2021 dengan Populasi seluruh penderita diabetes mellitus di Wilayah Kerja Puskesmas Kenali Besar berjumlah 178 orang, dengan teknik Total sampling dengan sampel sebesar 178 orang. Data diperoleh menggunakan kuesioner. Uji statistik digunakan adalah uji Chi-square. Hasil penelitian dikatakan berhubungan jika $p$ value $\leq 0,05$ dan dikatakan tidak berhubungan jika p value $>0,05$.

\section{HASIL DAN PEMBAHASAN}

Lama Menderita Diabetes Melitus

Tabel 1. Distribusi Frekuensi Gambaran Lama Menenderita Diabetes Melitus Di Wilayah Kerja Puskesmas Kenali Besar

\begin{tabular}{cccc}
\hline No. & $\begin{array}{c}\text { Lama } \\
\text { Menderita }\end{array}$ & Jumlah & $(\%)$ \\
\hline 1 & $>5$ tahun & 149 & 83,7 \\
2 & $\leq 5$ tahun & 29 & 16,3 \\
& Total & 178 & 100 \\
\hline
\end{tabular}

Berdasarkan tabel 1 dapat disimpulkan bahwa responden yang menderita diabetes 
mellitus >5 tahun lebih banyak dibandingkan responden yang menderita diabetes mellitus $<5$ tahun

\section{Indeks Massa Tubuh}

Tabel 2.Distribusi Frekuensi Gambaran Indeks Masa Tubuh Di Wilayah Kerja Puskesmas Kenali Besar

\begin{tabular}{clcc}
\hline No. & $\begin{array}{l}\text { Indeks Masa } \\
\text { Tubuh }\end{array}$ & Jumlah & $\mathbf{( \% )}$ \\
\cline { 2 - 4 } 1 & $\begin{array}{l}\text { Berat Badan } \\
\text { Lebih }\end{array}$ & 55 & 30,9 \\
2 & $\begin{array}{l}\text { Berat Badan } \\
\text { Normal } \\
\text { Total }\end{array}$ & 123 & 69,1 \\
& 178 & 100 \\
\hline
\end{tabular}

Berdasarkan tabel 2 dapat disimpulkan bahwa responden yang berat badan lebih normal lebih banyak dibandingkan dengan responden berat badan lebih.

Gejala Neoropati

Tabel 3. Distribusi Frekuensi Gambaran Gejala Neoropati Diabetes Melitus Di Wilayah Kerja Puskesmas Kenali Besar

\begin{tabular}{cccc}
\hline No. & $\begin{array}{c}\text { Gejala } \\
\text { Neuropati }\end{array}$ & Jumlah & $\mathbf{( \% )}$ \\
\cline { 2 - 4 } 1 & Berat & 102 & 57,3 \\
2 & Ringan & 76 & 42,7 \\
& Total & 178 & 100 \\
\hline
\end{tabular}

Berdasarkan tabel 3 dapat disimpulkan bahwa responden mempunyai gejala neuropati lebih banyak dibandingkan dengan responden yang gejala neuropati baik.

Tabel 4. Hubungan Lama Menderita Diabetes Mellitus Dengan Gejala Neuropati Pada Penderita Diabetes Mellitus Di Wilayah Kerja Puskesmas Kenali Besar Tahun 2021

\begin{tabular}{|c|c|c|c|c|c|c|c|c|}
\hline \multirow{3}{*}{ No } & \multirow{3}{*}{$\begin{array}{l}\text { Lama } \\
\text { Menderita }\end{array}$} & \multicolumn{4}{|c|}{ Gejala Neuropati } & \multirow{2}{*}{\multicolumn{2}{|c|}{ Total }} & \multirow{3}{*}{ P-value } \\
\hline & & \multicolumn{2}{|c|}{ Berat } & \multicolumn{2}{|c|}{ Ringan } & & & \\
\hline & & $\mathbf{N}$ & $\%$ & $\mathbf{N}$ & $\%$ & $\mathbf{N}$ & $\%$ & \\
\hline 1 & $>5$ tahun & 92 & 61.7 & 57 & 36.3 & 149 & 100 & 0.012 \\
\hline 2 & $\leq 5$ tahun & 10 & 34.5 & 19 & 65.5 & 29 & 100 & \\
\hline Total & & 102 & 57.3 & 76 & 42.7 & 178 & 100 & \\
\hline
\end{tabular}

Berdasarkan tabel 4 menunjukan dengan penurunan fungsi sel beta pankreas ada hubungan lama menderita diabetes mellitus dengan gejala neuropati pada penderita diabetes mellitus di Wilayah Kerja Puskesmas Kenali Besar Tahun 2021 $(P$-value $=0,012)$

Sejalan dengan penelitian Galvani (2020) Hasil uji statistik menggunakan korelasi spearman menunjukan adanya hubungan lama menderita DM tipe 2 dengan risiko neuropati ( $p$-value $=0,023$ )

Menurut Smeltzer dan Bare (2008) sehingga menimbulkan komplikasi yang secara umum terjadi pada pasien dengan lama sakit 5-10 tahun. Menurut Guyton (2007) dalam Suyanto (2016) penurunan fungsi sel beta pangkreas akan berdampak pada produksi insulin. Berkurangnya jumlah produksi insulin didalam darah akan menurunkan proses glikolisi didalam sel. Akibat glokusa yang tidak diserap oleh sel akan menyebabkan peningkatan akumulasi glukosa pada pembuluh darah dan lama waktu terdiagnosa DM juga berkaitan menjadikan kondisi hiperglikemik

Tabel 5. Hubungan Indeks Masa Tubuh Dengan Gejala Neuropati Pada Penderita Diabetes Mellitus Di Wilayah Kerja Puskesmas Kenali Besar Tahun 2021

\begin{tabular}{|c|c|c|c|c|c|c|c|c|}
\hline \multirow{3}{*}{ No } & \multirow{3}{*}{ IMT } & \multicolumn{4}{|c|}{ Gejala Neuropati } & \multirow{2}{*}{\multicolumn{2}{|c|}{ Total }} & \multirow{3}{*}{$P$-value } \\
\hline & & \multicolumn{2}{|c|}{ Berat } & \multicolumn{2}{|c|}{ Ringan } & & & \\
\hline & & $\mathbf{N}$ & $\%$ & $\mathbf{N}$ & $\%$ & $\mathbf{N}$ & $\%$ & \\
\hline 1 & Lebih & 38 & 70.9 & 16 & 29.1 & 55 & 100 & \multirow{3}{*}{0.022} \\
\hline 2 & Normal & 63 & 54.2 & 60 & 48.8 & 123 & 100 & \\
\hline & Total & 102 & 57.3 & 76 & 42.7 & 178 & 100 & \\
\hline
\end{tabular}


Berdasarkan tabel 5. diketahui dari Uji statistik menunjukan ada hubungan indeks masa tubuh dengan gejala neuropati pada penderita diabetes mellitus di Wilayah Kerja Puskesmas Kenali Besar Tahun 2021. $(P$ - value $=0,022)$

Sejalan dengan penelitisn Regina (2018) ada hubungan antara IMT dengan neuropati diabetika pada pasien DM tipe 2 $(\mathrm{P}-$ Value $=0,012)$.

Kelebihan berat badan $\geq 20 \%$ dari berat badan ideal IMT(Index Masa Tubuh ). Kegemukan menyebabkan berkurangnya jumlah reseptor insulin yang dapat bekerja di dalam sel pada otot skeletel dan jaringan lemak. Hal ini dikarenakan resistensi insulin perifer. Kegemukan juga merusak kemampuan sel beta untuk melepas insulin saat terjadi peningkatan glokosa darah (Damayanti, 2015).

Mengukur obesitas atau tidaknya seseorang (lemak tubuh) secVara lansung sangat sulit dan sebagai pengganti dipakai Body Mass Index (BMI) atau Indeks Massa Tubuh (IMT) yaitu perbandingan berat badan (dalam kilogram) dengan kuadrat tinggi badan malam meter. (Guyton, 2018)

Sejalan dengan penelitian Hartono (2016) Hasil penelitian dari 80 responden didapatkan data yaitu $16,25 \%$ pasien beresiko obesitas; $58,75 \%$ pasien dengan obesitas derajat $1,25 \%$ pasien dengan obesitas derajat 2,18 pasien $(22,5 \%)$ tidak/bukan diabetes melitus. 22 pasien $(27,5 \%)$ belum pasti diabetes melitus dan 40 pasien $(50.0 \%)$ dengan diabetes melitus.

\section{SIMPULAN}

Berdasarkan hasil penelitian maka dapat kesimpulan dalam penelitian ini adalah : Sebagaian besar responden menderita diabetes mellitus > 5 tahun $(83,7 \%)$, berat badan lebih $(69,1 \%)$, dan mempunyai gejala neuropati kurang baik $(57,3 \%)$, Ada hubungan yang bermakna antara lama menderita diabetes mellitus dengan gejala neuropati pada penderita diabetes mellitus di Wilayah Kerja
Puskesmas Kenali Besar Tahun 2021 dengan $p$-value $=0,012$, Ada hubungan yang bermakna antara indeks masa tubuh dengan gejala neuropati pada penderita diabetes mellitus di Wilayah Kerja Puskesmas Kenali Besar Tahun 2021 dengan $p$-value $=0,022$

\section{SARAN}

Disarankan pada pihak Puskesmas diharapkan dapat membuat berbagai sarana promosi kesehatan dalam pencegahan gejala neoropati pada pasien diabetes mellitus seperti penyuluhan langsung pada pasien maupun dengan media leaflet, poster dan spanduk.

\section{DAFTAR PUSTAKA}

Anggun, 2020. Faktor-faktor yang Mempengaruhi Derajat Keparahan Neuropati Perifer Pada Pasien Diabetes Melitu. Jurnal Imlu Keperawatan Vol. 8 No. 1. Diakses pada tanggal 10 Maret 2021.http://jurnal.unsyiah.ac.id/JIK/ article/view/17892

Arikunto, S. 2013.Prosedur Penelitian Suatu Pendekatan Praktik. Edisi Revisi. Jakarta: PT. Rineka Cipta

Bilous, 2014. Buku Pegangan Diabetes Edisi Ke 4. Penerbit Bumi Medika. Jakarta.

Damayanti, 2015. Diabetes Melitus dan Penatalaksanaan Keperawatan. Penerbit Medical Book. Yogyakarta.

Ernawati, 2013. Penatalaksaan Keperawatan Diabetes Melitus. Penerbit Mitra Wacana Media; Jakarta

Eliana, F. 2015. Penatalaksanaan diabetes mellitus sesuaikonsensusperkeni. Satelit symposium 6.1 DM Update dan $\mathrm{Hb} 1 \mathrm{c}$

Galvani Volta Simanjuntak(2020) Lama menderita diabetes mellitus tipe 2 sebagai faktor risiko neuropati perifer diabetic. Holistik Jurnal 
Kesehatan, Volume 14, No.1, Maret2020 : 96-100

Guyton, A. C., Hall, J. E., 2014. Buku Ajar Fisiologi Kedokteran. Edisi 12. Jakarta : EGC, 1022

Manurung, N. 2018 Keperawatan Medikal Bedah Konsep, Mind Mapping dan NANDA NIC NOC.Jakarta : TIM

Nugroho, 2011. Asuhan Keperawatan Maternitas, Anak, Bedah dan Penyakit Dalam. Penerbit Nuha Medika; Yogyakarta.

Perkeni, 2015. Indonesia,P.Epengelolaan dan pencegahan diabetes mellitus tipe 2 diindonesia. PB Perkeni

Rima, 2020. Factor resiko neuropat iperifer diabetik pada pasien diabetes melitustipe 2. Jurnal Keperawatan Vol. 3 No. 2. Diaksespadatanggal 10 Maret 2021.http://jurnal.univrab.ac.id/inde x.php/keperawatan/article/view/839

Rina, 2016. Faktor-FaktorRisikoKejadian Kaki DiabetikpadaPenderita Diabetes MelitusTipe 2 (StudiKasusKontrol di RSUP dr. M. Djamil Padang). Jurnal Epidemiologi Kesehata Komunitas Vol 1 No. 2. Diaksespadatanggal 10 Maret 2021.https://ejournal2.undip.ac.id/in dex.php/jekk/article/view/3943/219 $\underline{2}$

Suiraoka, 2012. Penyakit Degeneratif. Penerbit Nuha Medika. Yogyakarta 